\title{
In Memoriam: Mario Giovanni Terzano, MD (1944-2020): Father of the Cyclic Alternating Pattern in Sleep
}

\author{
Liborio Parrino ${ }^{1}$ (D) \\ Published online: 25 January 2021 \\ (c) The Author(s), under exclusive licence to Springer Nature Singapore Pte Ltd. part of Springer Nature 2021
}

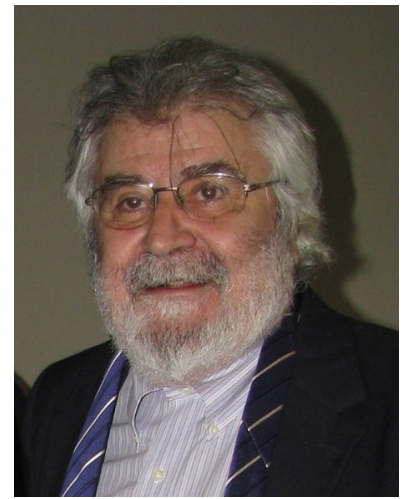

I began studying and learning about sleep thanks to my mentor Professor Mario Giovanni Terzano, for friends he was simply Nanni. When I arrived at the University of Parma in 1981, just graduated and full of enthusiasm, Nanni welcomed me with cold and disarming realism: if you work with me I do not promise to get you hired at the clinic but I will teach you everything I know. If you are good and patient, one day this will serve you for your career. I realized that I would have to sweat a lot to keep up with a brilliant, creative, and above all unconventional mind. His vast culture ranged beyond medicine and neurology, reaching high levels also in the fields of architecture, botany, ancient books, and oriental religions. He was also a yoga teacher and thanks to the rigorous control of the mind and body he was able to give birth to the innovative concept of mental and vegetative stability of the sleeping brain.

For several years, we worked without any computers at night. In the evening, the technicians mounted the electrodes on the patient's head and then put him to bed. We were volunteer shift workers willing to lose the night to

Liborio Parrino

liborio.parrino@unipr.it

1 Sleep Disorders Center, University of Parma, Parma, Italy observe sleep closely, to listen to it, protect it, stimulate it. Explorers hypnotized by the sound of the metal nibs in the silence of the laboratory, enraptured by the flow of paper that accumulated in gigantic piles like the pillars of a cathedral. On the paper, the nibs drew the traces of brain waves, symbols of the mysterious language of the brain. Here come the arousals, organized in sequences like swarms of herons in flight. Here is Terzano's great intuition: those events, apparently trivial, form a design, a clear and recognizable plot: the cyclic alternating pattern or CAP [1]. Initials coined in Parma, but which have become a famous acronym all over the world as a synonym for the microstructure of sleep [2]. During CAP, the brain waves oscillate in a perfect dance in tune with the rest of the body [3]. Without CAP there is no balance, there is no cohesion among the various systems that allow us to survive in the unconsciousness of sleep.

Thanks to the discovery and clinical applications of CAP [4], Terzano becomes an internationally renowned scholar even if the resistance against the new vision of sleep sometimes takes on impetuous polemical tones. But the studies on sleep microstructure confirm the original intuition. Time is always an honest man. In the year 2000, leading sleep experts from North America visited Parma to grant Terzano and his school the honor of arms [5]. Meanwhile, Nanni was promoted to the level of a full professor of Neurology, and subsequently, he was elected as the prestigious President of the Italian Association of Sleep Medicine (AIMS). In 2012, he received the Pisa Sleep Award, and subsequently, in 2016, he was awarded the Antonio Arrigo international award in the wake of the prestigious tradition of Italian clinical neurophysiology.

Nanni's teaching work continued unceasingly and generously. The Sleep Medicine Center that was founded by Professor Terzano became a premier sleep research and training laboratory of the European Sleep Network, hosting numerous scholars who come from all over the world to learn the fundamental aspects and significance of CAP 
during sleep [6-14] and to listen from the giant in the field. His countless students remember him and appreciate his passion for research, humility, and originality of his thinking. Nanni is never confined to the narrow boundary of isolated specialization, but always in search of the intersection and a broader perspective of the scientific problem. Thank you, Nanni, for your curiosity and your intelligence and for never having feared the harsh but sincere confrontation. Thank you for sharing those magical nights when sleep became a fascinating and unique model for studying the hidden side of physiology, medicine, and life.

\section{References}

1. Terzano MG, Mancia D, Salati MR, Costani G, Decembrino A, Parrino L. The cyclic alternating pattern as a physiologic component of normal NREM sleep. Sleep. 1985;8:137-45.

2. Terzano MG, Parrino L. Functional relationship between microand macrostructure of sleep. In: Terzano MG, Halasz P, Declerck AC, editors. Phasic events and dynamic organization of sleep. New York: Raven Press; 1991. p. 101-19.

3. Terzano MG, Parrino L. Origin and significance of the cyclic alternating pattern (CAP). Sleep Med Rev. 2000;4:101-23.

4. Terzano MG, Parrino L. Clinical applications of cyclic alternating pattern. Physiol Behav. 1993;54:807-13.

5. Terzano MG, Parrino L, Smerieri A, Chervin R, Chokroverty S, Guilleminault C, Hirshkowitz M, Mahowald M, Moldofsky H, Rosa A, Thomas R, Walters A. Atlas, rules, and recording techniques for the scoring of cyclic alternating pattern (CAP) in human sleep. Sleep Med. 2001;2:537-53.

6. Zucconi M, Oldani A, Ferini-Strambi L, Smirne S. Arousal fluctuations in non-rapid eye movement parasomnias: the role of cyclic alternating pattern as a measure of sleep instability. J Clin Neurophysiol. 1995;12:147-54.

7. Ferrillo F, Gabarra M, Nobili L, Parrino L, Schiavi G, Stubinski $\mathrm{B}$, Terzano MG. Comparison between visual scoring of cyclic alternating pattern (CAP) and computerized assessment of slow EEG oscillations in the transition from light to deep non-REM sleep. J Clin Neurophysiol. 1997;14:210-6.

8. Bruni O, Miano S, Verrillo E, Vittori E, Della Marca G, Farina B, Mennuni G. Sleep cyclic alternating pattern in normal school-age children. Clin Neurophysiol. 2002;113:1806-14.

9. Thomas RJ, Terzano MG, Parrino L, Weiss JW. Obstructive sleepdisordered breathing with a dominant cyclic alternating patterna recognizable polysomnographic variant with practical clinical implications. Sleep. 2004;27:229-34.

10. Guilleminault C, Lopes MC, Hagen CC, da Rosa A. The cyclic alternating pattern demonstrates increased sleep instability and correlates with fatigue and sleepiness in adults with upper airway resistance syndrome. Sleep. 2007;30:641-7.

11. Ferri R, Huber R, Aricò D, Drago V, Rundo F, Ghilardi F, Massimini $\mathrm{M}$, Tononi $\mathrm{G}$. The slow-wave components of the cyclic alternating pattern (CAP) have a role in sleep-related learning processes. Neurosci Lett. 2008;432:228-31.

12. Halasz P, Bódizs R, Parrino L, Terzano M. Two features of sleep slow waves: homeostatic and reactive aspects-from long term to instant sleep homeostasis. Sleep Med. 2014;15:1184-95.

13. Giorgi FS, Maestri M, Guida M, Carnicelli L, Caciagli L, Ferri R, Bonuccelli U, Bonanni E. Cyclic alternating pattern and interictal epileptiform discharges during morning sleep after sleep deprivation in temporal lobe epilepsy. Epilepsy Behav. 2017;73:131-6.

14. Congiu P, Mariani S, Milioli G, Parrino L, Tamburrino L, Borghero G, Defazio G, Pereira B, Fantini ML, Puligheddu M. Sleep cardiac dysautonomia and EEG oscillations in amyotrophic lateral sclerosis. Sleep. 2019;42:zsz64.

Publisher's Note Springer Nature remains neutral with regard to jurisdictional claims in published maps and institutional affiliations. 